\title{
Review \\ Effect of Foot Orthoses and Shoes in Parkinson's Disease Patients: A PRISMA Systematic Review
}

\author{
María Reina-Bueno $^{1}\left(\mathbb{D}\right.$, César Calvo-Lobo ${ }^{2} \mathbb{D}$, Daniel López-López ${ }^{3} \mathbb{D}$, Patricia Palomo-López ${ }^{4}(\mathbb{D}$, \\ Ricardo Becerro-de-Bengoa-Vallejo ${ }^{2} \mathbb{D}$, Marta Elena Losa-Iglesias ${ }^{5}\left(\mathbb{D}\right.$, Carlos Romero-Morales ${ }^{6, *(\mathbb{D})}$ \\ and Emmanuel Navarro-Flores ${ }^{7}$ (D)
}

check for

updates

Citation: Reina-Bueno, M.;

Calvo-Lobo, C.; López-López, D.;

Palomo-López, P.;

Becerro-de-Bengoa-Vallejo, R.;

Losa-Iglesias, M.E.; Romero-Morales,

C.; Navarro-Flores, E. Effect of Foot

Orthoses and Shoes in Parkinson's

Disease Patients: A PRISMA

Systematic Review. J. Pers. Med. 2021,

11, 1136. https://doi.org/10.3390/

jpm11111136

Academic Editors: Dag Nyholm and Filip Bergquist

Received: 5 October 2021

Accepted: 29 October 2021

Published: 2 November 2021

Publisher's Note: MDPI stays neutral with regard to jurisdictional claims in published maps and institutional affiliations.

Copyright: (c) 2021 by the authors. Licensee MDPI, Basel, Switzerland. This article is an open access article distributed under the terms and conditions of the Creative Commons Attribution (CC BY) license (https:// creativecommons.org/licenses/by/ $4.0 /)$.
1 Faculty of Nursing, Physiotherapy and Podiatry, University of Sevilla, 41009 Seville, Spain; mreina1@us.es

2 Faculty of Nursing, Physiotherapy and Podiatry, Complutense University of Madrid, 28040 Madrid, Spain; cescalvo@ucm.es (C.C.-L.); ribebeva@ucm.es (R.B.-d.-B.-V.)

3 Research, Health and Podiatry Group, Department of Health Sciences, Faculty of Nursing and Podiatry, Universidade da Coruña, 15403 Ferrol, Spain; daniellopez@udc.es

4 University Center of Plasencia, Universidad de Extremadura, 10600 Plasencia, Spain; patibiom@unex.es

5 Faculty of Health Sciences, Universidad Rey Juan Carlos, 28922 Alcorcón, Spain; marta.losa@urjc.es

6 Faculty of Sport Sciences, Universidad Europea de Madrid, 28670 Villaviciosa de Odón, Spain

7 Frailty Research Organized Group (FROG), Department of Nursing, Faculty of Nursing and Podiatry, University of Valencia, 46010 Valencia, Spain; emmanuel.navarro@uv.es

* Correspondence: carlos.romero@universidadeuropea.es; Tel.: +34-912-115-268

\begin{abstract}
Reduced plantar foot sensation, postural instability, and gait difficulties are characteristic of Parkinson's disease patients. A systematic review was carried out to determine the effect of the different types of insoles and shoes in these patients. Several databases were used to search for relevant articles reporting Parkinson's disease patients undergoing treatment with any type of insole and footwear. All titles and abstracts were reviewed independently by two reviewers and the available data were extracted. The study eligibility criteria were any type of experimental study that included Parkinson's disease patients treated with any type of insole or footwear. Eight studies were selected. Interventions used were textured insoles, footwear modifications, and habitual footwear. Three different outcomes were evaluated in each study: gait parameters, balance, and plantar sensation. According to the data available from this systematic review, the most important conclusion is that more controlled studies are needed in this research field. There are indications to suggest that textured insoles have positive effects on gait parameters, balance, and plantar sensation in Parkinson's disease patients.
\end{abstract}

Keywords: insole; Parkinson's disease; footwear; balance; gait

\section{Introduction}

Failure of the dopaminergic cells in the substantia nigra pars compacta is the main pathology in Parkinson's disease (PD), causing a reduced dopamine level in the basal ganglia [1]. PD results in typical motor abnormalities, from drive to gait impairment and postural instability. The main characteristics of abnormal gait in PD are a slow walking speed, increased stride variability, and short shuffling steps [2].

An anomaly related to the striatum (caudate and putamen) can result in "striatal deformity" - atypical postures of the hand, spine or foot [3]. These deformities may be responsive to levodopa and may be part of the process of the wearing off of dystonia. Misdiagnosis of these deformities as rheumatoid or as some other type of arthritis is very common. Initially these deformities may be flexible, but later they become rigid [4].

The hands and/or feet joints can develop rheumatoid-like deformities; these Parkinsonian signs are poorly known and unrecognized. The types of striatal foot involve equinovarus foot positioning, flexion of the other toes, and great toe extension. Foot deformities disturb gait and stability and produce supplementary disability in patients, adding 
to the complexity of PD symptoms. Deformities can also produce pain, distress cramp, muscle tension, and may impair the ability to wear shoes. If untreated, skin ulceration, contractures, abnormal gait patterns, and bone erosion may occur [5].

The degeneration of the peripheral sensory nerves and cutaneous receptors can reduce peripheral sensation in people with PD [6]. Abnormal kinesthesia and proprioception contribute to the Parkinsonian gait, even though PD is mainly a motor disease, adding evidence suggesting that PD patients have impaired joint position sense and reduced plantar foot sensation, movement accuracy, and movement perception. A defective proprioceptive feedback and an inadequate integration of sensory inputs induce the abnormal motor control movement in PD [7].

These gait disorders severely restrict patients' quality of life and mobility and augment the risk of falling $[8,9]$. The link of falls with femoral fractures, increased dependency, social isolation, and lowered quality of life because of the fear of falling explains their importance [10].

Striatal limb deformities develop in approximately $13 \%$ of patients with PD [5]. Reduced plantar foot sensation, postural instability, and gait difficulties are characteristic of PD patients [11]. The use of footwear in these patients reduces peripheral feedback from the feet and restricts foot structure. It has a negative influence on foot functionality [9]. Footwear is a modifiable risk factor in falls prevention. Gait patterns can be altered by footwear [12]. Although pharmacological intervention is the pillar of Parkinson's treatment, there is weak evidence to indicate that drug therapy reliably increases balance to reduce falls [10].

Therefore, we performed a systematic review to determine how different footwearbased interventions (textured insoles, footwear modifications, and habitual footwear) affect the outcome (gait parameter, balance, and plantar sensation) in PD patients.

\section{Materials and Methods}

\subsection{Identification, Eligibility Criteria, and Selection of Studies}

This systematic review was registered in PROSPERO. The title decided on was "Effect of foot orthoses and shoes in Parkinson's disease patients", and the registration number assigned was CRD42020209824. The search took place in the following databases: MEDLINE, Dialnet, Scopus, Web of Science, and The Cochrane Library.

The searches were performed in October 2020, after constructing the strategies to be used in the different databases and after developing a succession of pilot tests to verify the exact implementation of the procedure in each of them. The search strategy carried out can be checked in the Supplementary Materials.

The descriptors foot orthoses, insoles, shoes, and footwear were used, combined with AND Parkinson. The descriptors relating to the terms of relevance were used with CINAHL, PubMed, and The Cochrane Library databases, as well as with the free terms. In all of these, an advanced search tool was employed to create the strategy.

Initially, only randomized controlled clinical trials (RCTs) written in English language and up to 10 years old were selected, but due to the limited number of studies found, the selection criteria were broadened. Neither the language of the documents nor the year of publication were restricted. The inclusion criteria were any type of experimental study, whether RCT, non-randomized controlled clinical trial, non-controlled clinical trial or crossover clinical trial) with Parkinson's patients of any age, sex, race, or ethnicity. If one of them included the application of any type of insole and/or use of any type of footwear, any kind of comparison between interventions was acceptable. The use of additional physical treatment, orthotics, and/or complementary pharmacological treatment was not a cause for exclusion. Any kind of result was valid.

\subsection{Assessment of Characteristics of Studies}

Two independent reviewers (M.R.B. and E.N.F.) developed the selection procedure. Each evaluator read the title and abstract of each of the documents; independently, they 
assessed whether each of studies met the inclusion criteria. Independently each reviewer assessed the main characteristics of the studies, indicating whether they matched the eligibility criteria.

Thus, after the first negative item showed, each reviewer could reject the document without the requirement of continuing to assess the rest of it.

The risk of bias evaluation in the studies was carried out using the Review Manager tool (RevMan) of The Cochrane Library, v.5.3. Once obtained, a complete reading of the documents chosen by each of the reviewers was performed, again separately. In the complete reading, we again evaluated its suitability according to precise compliance with the inclusion criteria defined, which was required for the study to be finally chosen for review.

\subsection{Data Extraction}

To simplify the first selection procedure, due to the high number of references analyzed, an Excel page was designed as a data collection form in which the inclusion or non-inclusion of the document and the reason for its elimination were recorded via a codification of the items (criteria). Each reviewer processed his/her own page.

After the first evaluation of the reports, their results were combined, and the inclusion or exclusion of the contradictory documents was debated. The inclusion or exclusion was debated by the two initial reviewers, but on occasion, the mediation of a third reviewer (D.L.L.) was required to decide the final inclusion or exclusion of some of the documents due to the absence of agreement between the first two reviewers.

Lastly, a single reviewer (M.R.B.) performed the full data extraction of the documents finally selected in the second evaluation. A continuation of the initial Microsoft Word format data collection form was created to take note of the general information described in the study; both its identification (ID study or report) and its main characteristics (type of participants, interventions, results, etc.) again centered on compliance with the eligibility criteria defined in the review.

The Microsoft Word forms were based on the adaptation and translation of the current model conceived by The Cochrane Collaboration for RCTs [13].

\section{Results}

The distinct phases of the selection procedure of the studies definitively included in the review are presented in Figure 1, for which a flow diagram was utilized, based on the one established by the PRISMA declaration [13-15]. 


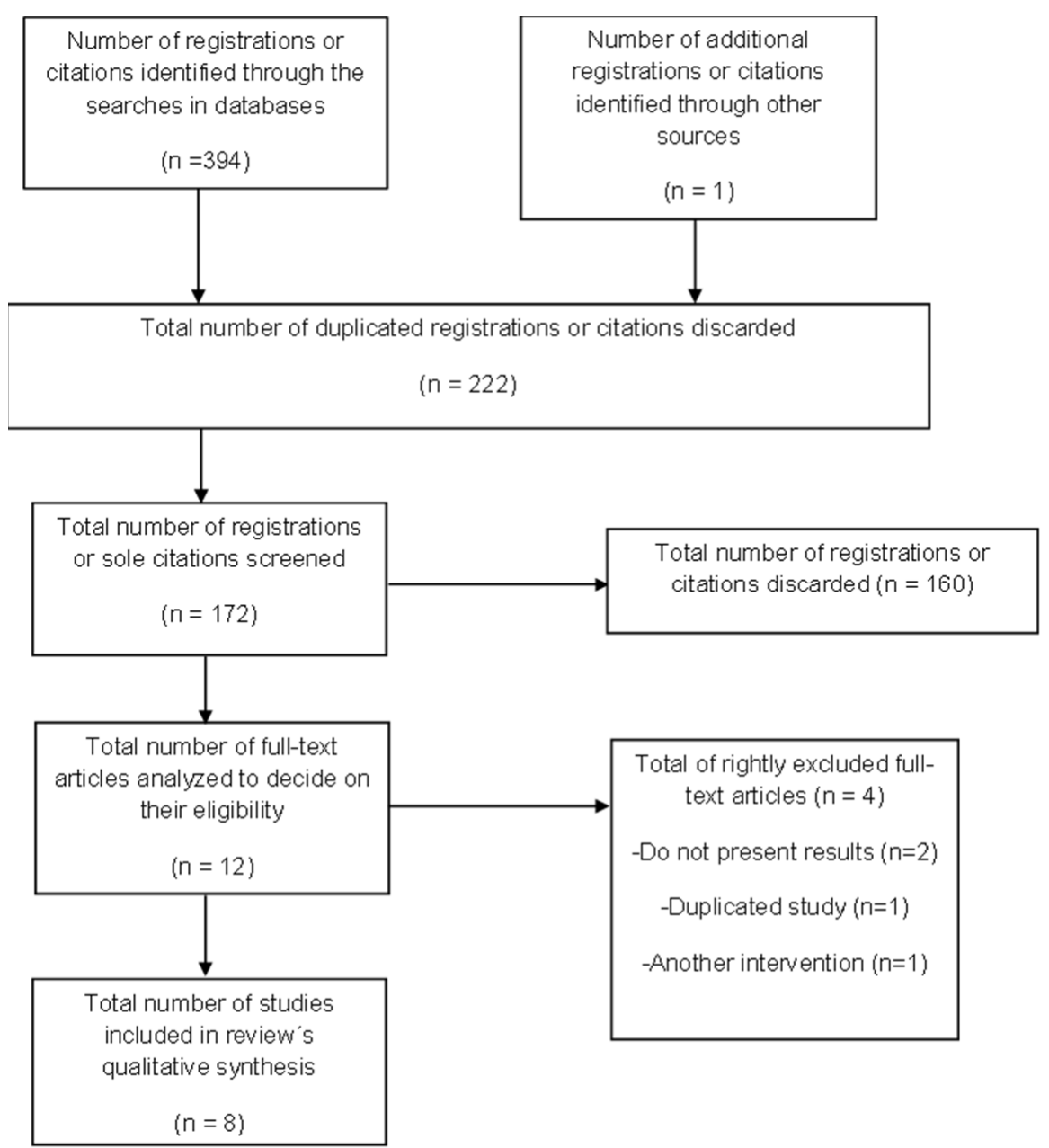

Figure 1. Distinct phases of the selection procedure of the studies involved in the review.

The design of the PICO question was based on the study selection criteria $[13,16,17]$ (Table 1).

Table 1. Elements of the PICO question.

\begin{tabular}{llll}
\hline $\mathbf{P}$ & Participants & Study population & Parkinson's patients \\
\hline $\mathbf{I}$ & Intervention & $\begin{array}{l}\text { Interesting } \\
\text { intervention }\end{array}$ & Insole and/or footwear \\
\hline $\mathbf{C}$ & Comparison & Comparison used & Any \\
\hline $\mathbf{O}$ & Outcomes & Results obtained & Any \\
\hline $\mathbf{S}$ & Study design & Type of study & Any type of experimental studies \\
\hline
\end{tabular}

A synopsis of the data extracted related to the most important characteristics of the main parts of each study is presented in Table 2 . 

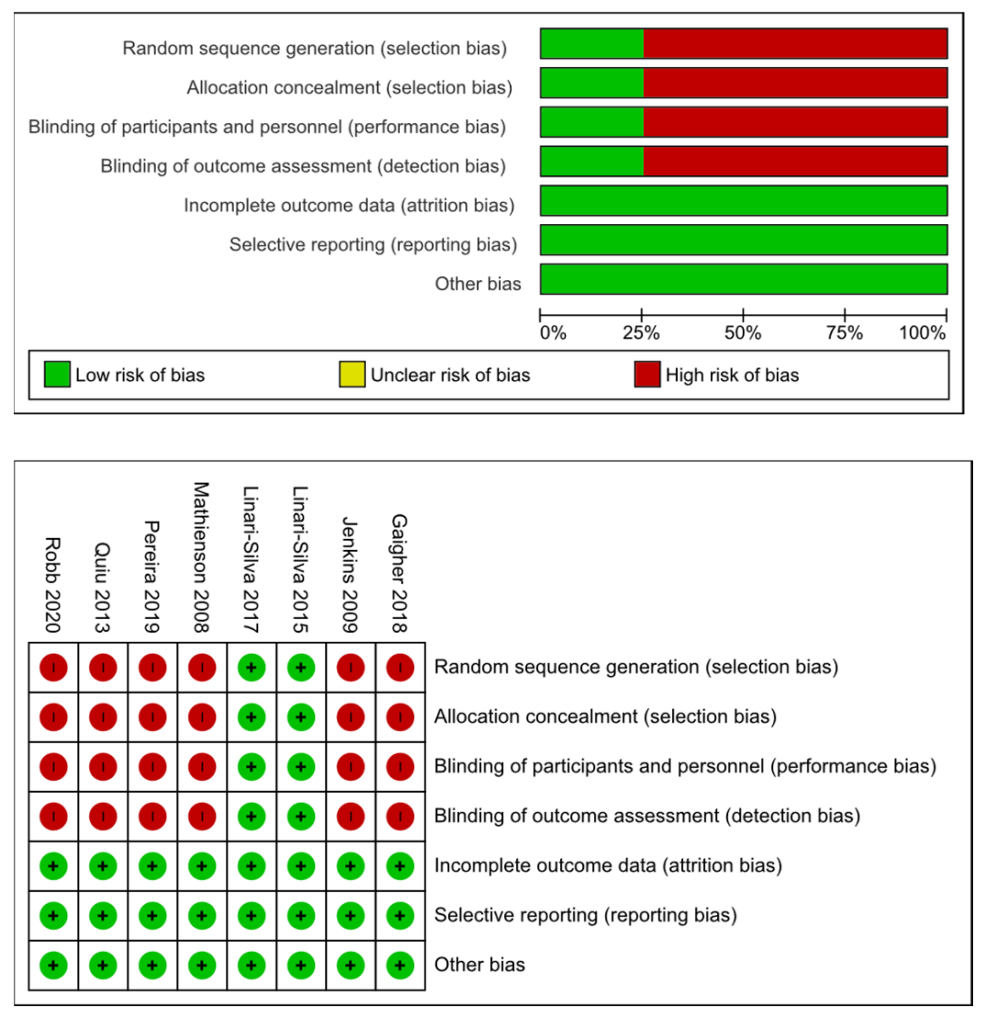

Figure 2. Risk of bias in the studies included. Green: Low risk of bias. Red: High risk of bias.

Table 2. Main characteristics of the studies included.

\begin{tabular}{|c|c|c|c|c|c|c|c|}
\hline & Participants & Men & Women & $\begin{array}{l}\text { Average Age } \\
\text { (Years) }\end{array}$ & Type of Treatment & $\begin{array}{c}\text { Study } \\
\text { Duration }\end{array}$ & $\begin{array}{c}\text { Results } \\
\text { Measured }\end{array}$ \\
\hline Gaigher 2018 & 2 & 2 & & 85 & $\begin{array}{l}\text { Textured insoles } \\
\text { (thermoformed soles } \\
\text { covered with textured } \\
\text { material) }\end{array}$ & Two weeks & Postural stability \\
\hline Jenkins 2009 & $\begin{array}{l}40 \text { Parkinson's } \\
\text { patients } \\
40 \text { control group }\end{array}$ & 39 & 41 & $\begin{array}{l}64.73 \pm 7.66 \\
65.40 \pm 8.01\end{array}$ & $\begin{array}{l}\text { Textured insoles } \\
\text { (facilitatory (ribbed) insole) } \\
\text { Conventional (flat) insoles }\end{array}$ & $\begin{array}{l}\text { Immediate } \\
\text { effect }\end{array}$ & $\begin{array}{l}\text { Gait parameters } \\
\text { Dynamic } \\
\text { stability }\end{array}$ \\
\hline $\begin{array}{l}\text { Lirari-Silva } \\
2015\end{array}$ & $\begin{array}{l}19 \text { Parkinson's } \\
\text { patients } \\
19 \text { control group }\end{array}$ & 20 & 18 & $\begin{array}{l}71.84 \pm 6.64 \\
71.73 \pm 6.64\end{array}$ & $\begin{array}{l}\text { Conventional insoles } \\
\text { Textured insoles (with } \\
\text { half-spheres) } \\
\text { Textured insoles (with a } \\
\text { raised ridge around the foot } \\
\text { perimeter) }\end{array}$ & $\begin{array}{l}\text { Immediate } \\
\text { effect }\end{array}$ & $\begin{array}{l}\text { Gait parameters } \\
\text { Plantar sensation }\end{array}$ \\
\hline $\begin{array}{l}\text { Lirari-Silva } \\
2017\end{array}$ & $\begin{array}{l}10 \text { experimental } \\
\text { group } \\
9 \text { control group }\end{array}$ & & & $\begin{array}{l}70.4 \pm 6.87 \\
72 \pm 6.2\end{array}$ & $\begin{array}{l}\text { Textured insoles (with } \\
\text { half-spheres) } \\
\text { Conventional insoles }\end{array}$ & One week & $\begin{array}{l}\text { Gait parameters } \\
\text { Plantar sensation }\end{array}$ \\
\hline $\begin{array}{l}\text { Mathieson } \\
2008\end{array}$ & $\begin{array}{l}1 \text { Parkinson's } \\
\text { patient }\end{array}$ & & & & Footwear modification & $\begin{array}{l}\text { Immediate } \\
\text { effect }\end{array}$ & Gait parameters \\
\hline Pereira 2019 & $\begin{array}{l}16 \text { Parkinson's } \\
\text { patients } \\
15 \text { control group }\end{array}$ & 13 & 18 & $\begin{array}{l}69.19 \pm 7.25 \\
70.80 \pm 5.51\end{array}$ & Habitual footwear & $\begin{array}{l}\text { Immediate } \\
\text { effect }\end{array}$ & Gait parameters \\
\hline Qiu 2013 & $\begin{array}{l}20 \text { Parkinson's } \\
\text { patients } \\
20 \text { control group }\end{array}$ & 26 & 14 & $\begin{array}{l}65 \pm 9 \\
69 \pm 5\end{array}$ & $\begin{array}{l}\text { Smooth insoles } \\
\text { Textured insoles }\end{array}$ & $\begin{array}{l}\text { Immediate } \\
\text { effect }\end{array}$ & Static balance \\
\hline Robb 2020 & $\begin{array}{l}7 \text { Parkinson's } \\
\text { patients }\end{array}$ & 2 & 5 & $71.5 \pm 8.3$ & $\begin{array}{l}\text { Conventional insoles } \\
\text { Textured insoles }\end{array}$ & Five weeks & $\begin{array}{l}\text { Dynamic balance } \\
\text { Gait parameters }\end{array}$ \\
\hline
\end{tabular}


Of the eight studies included, two were RCTs $[8,16]$, and the other six were noncontrolled clinical trials $[1,6,9,10,18,19]$. The full number of participants in all the studies was 218 (102 men and 96 women; two studies did not specify the participants' genders). The age ranged from $64.73 \pm 7.66$ to 85 years old. All the studies were conducted on adults. Interventions used were textured insoles [1,6,8,16-18], footwear modification [10], and habitual footwear [9]. There were nine types of comparisons used: textured insole vs. basal [18], textured insoles vs. conventional insoles [1,6,8,16,18], footwear modification vs. basal [10], habitual footwear vs. barefoot [9]. These outcomes were evaluated in the different studies: gait parameters $[1,8,10,16]$, balance $[6,17]$, and plantar sensation $[8,16]$.

To better present the analysis of the studies, they were categorized according to the interventions used: textured insoles, footwear modification, and habitual footwear.

There were six studies regarding the effect of textured insoles in Parkinson's patients $[1,6,8,16-18]$.

Jenkins et al. 2009 [1] concluded there was an improvement of the gait pattern and dynamic stability. These produced an important rise in single-limb support time at the time of the initial ground contact, with the muscle activation sequence of the tibialis anterior being normalized.

In addition, Robb and Perry [18] observed that the use of textured insoles improved dynamic stability. This treatment modified the mass-base center of the support relationship. This study also showed benefits in turning performance.

Qui et al. 2013 [6] showed that this type of treatment improved postural stability, and decreased medial-lateral sway and standard deviation. In a study involving only two patients, Gaigher et al. [17] came to the same conclusion. Textured insoles improved postural stability in the most severe patients.

However, in Lirani-Silva et al. [8] there were no immediate benefits on gait with the use of textured insoles. These same authors [16] evaluated the effects one-week after the intervention and then after a one-week follow-up period. For one week, this insole amended stride length and the plantar sensation; however, only benefits in the plantar sensation were conserved after the follow-up period.

According to these studies, textured insoles would have a beneficial effect on patients with Parkinson's disease, improving stability, plantar sensation, and gait parameters.

Regarding modifications in footwear, only one clinical case has been published by Mathieson et al. [10], describing the effect of applying an external forefoot sagittal plane wedge to raise the toes off the ground. This analysis revealed augmented step length, improved foot-strike position with the ankle nearer to a neutral to marginally dorsiflexed position, and longer midstance phase with a longer heel contact period, contrasting with the rapid unloading that distinguishes Parkinson's gait. The author hypothesized that this footwear modification could have a role to play in the treatment of gait dysfunction in Parkinson's disease.

In regard to the influence of wearing regular footwear compared with walking barefoot, the study carried out by Pereira et al. [9] indicated an undesirable effect of footwear on gait spatiotemporal parameters in healthy people and those with PD. PD patients showed reduced time in the swing phase and had an augmented step width variability, duration, and step width length with footwear and higher step velocity asymmetry.

Although there were very few studies on the influence of footwear in these patients, there are indications that regular footwear could have a negative influence and that modifications in footwear could be useful in their treatment.

\section{Discussion}

Lower limb problems (gait, plantar sensation, and deformities) are one of the main characteristics of PD patients [3,6,7]. Postural and motor deficiencies are among the most incapacitating symptoms for patients with PD, disturbing their quality of life [19]. These conditions respond poorly to pharmacological treatment, so it is important to consider new actions and approaches [12]. The objective of this systematic review was to determine the 
effect of different types of insoles and footwear in PD patients. Eight studies fulfilled the inclusion criteria and were incorporated in the review for analysis. Due to the heterogeneity detected among the interventions implemented and the use of diverse instruments for the assessment of the results, it was decided to implement a qualitative synthesis of the outcomes.

It was detected that the studies involved could be assembled into three groups according to the intervention: textured insoles [1,6,8,16-18], footwear modification [10], and habitual footwear [9].

Textured insoles are a type of treatment that has been studied in the most depth in these patients. Some investigations concluded that the effect of these treatments was positive for PD patients.

According to these studies, textured insoles would have an immediate beneficial effect on patients with Parkinson's disease, improving stability and gait parameters.

Jenkins et al. 2009 [1] and Robb and Perry [19] concluded there was an improvement in dynamic stability. Jenkins et al. 2009 [1] concluded there was an improvement in the gait pattern.

Qui et al. 2013 [6] and Gaigher et al. [17] demonstrated that this type of treatment improved postural stability.

However, for Lirani-Silva et al. [8], with the use of textured insoles there were no immediate benefits on gait. These same authors [16] showed the effects one week after the intervention and after a one-week follow-up period. For one week, this insole amended the plantar sensation and gait pattern; however, only the improvement in the plantar sensation was preserved after the follow-up period. This could be due to the brief treatment period, only one week. It would be necessary to test the long-term effect of this type of treatment.

Although these studies proved that textured insoles had a beneficial effect on PD patients, only the investigations by Lirani-Silva et al. $[8,16]$ were RCTs, the others being non-controlled clinical trials. Only Lirani-Silva et al. 2017 [16] checked the efficacy of the treatment after a follow-up period. Thus, to assess the beneficial effect of textured insoles, it would be necessary to carry out RCTs with a follow-up period.

We believe that the positive effects of this type of insole are due to plantar stimulation. Other treatments, such as plantar foot stimulation, had a positive effect on stability and gait parameters, as demonstrated by Brognara et al. in their study [2].

These variations may lead to improvement in the plantar sensation, stability, and gait parameters. It could be a convenient treatment strategy for upgrading gait quality and reducing the risk of falls in individuals with $P D$.

Regarding modifications in footwear, only one clinical case was published by Mathieson et al. [10], describing the effect of the application of an external forefoot sagittal plane wedge on raising the toes off the ground. The author hypothesized that this footwear modification could have a role in the treatment of gait dysfunction in PD. However, this type of intervention would not be recommended for most Parkinson's patients because of the high prevalence of equine foot in these patients-which is $71.7 \%$ according to an observational study conducted in 2021—which would hinder the efficacy and compliance with this treatment [12].

As to the influence of wearing regular footwear compared with walking barefoot, the study carried out by Pereira et al. [9] showed a negative effect of footwear on gait spatiotemporal parameters in people with PD and healthy people. We believe that the effect on the gait parameters is due to the extra weight given by the footwear since footwear reduces peripheral feedback from the feet. The use of shoes decreases the flight phase and makes the gait more unstable and therefore more variable.

Regarding the influence of footwear on gait pattern in PD patients, modifications in footwear could have a positive effect. However, the effect of habitual footwear could be negative. According to the study by Novo-Trillo et al., a large proportion of participants with PD wear inappropriate footwear (in width, length, or both). Despite the influence that footwear has on walking and the great variability of footwear and its modifications, 
there are only two studies on this in PD patients. Further research would be necessary to demonstrate the effect of different types of footwear as well as their modifications in these patients: RCTs with a follow-up period. Due to the high prevalence of gait problems in these patients and the importance of footwear, it would be necessary to determine the recommended characteristics of footwear to minimize their negative effects and maximize their positive effects.

Together with dopamine-mimetic treatment, non-pharmacological treatment, like different types of insoles and shoes, could play a very important role in blocking motor symptoms, mainly for symptoms less receptive to pharmacological therapy since these symptoms tend to not respond satisfactorily to traditional therapy.

Authors should discuss the results and how they can be interpreted in the context of previous studies and their own working hypotheses. The findings and their implications should be discussed in the broadest context possible. Future research directions may also be highlighted.

Due to the small number of available RCTs, it was decided to expand the inclusion criteria by accepting any type of experimental study (randomized controlled clinical trials, non-randomized controlled clinical trials, non-controlled clinical trials, or crossover clinical trials). Of the eight studies included, two were RCTs $[8,16]$, and the other six were noncontrolled clinical trials $[1,6,9,10,17,18]$. The two RCTs were about investigated the effect of different textured insoles, and only Linari-Silva et al. [16] proved efficacy after a followup period.

Despite the high percentage of patients with biomechanical problems such as claw toes and clubfoot [5], we emphasize that no research on foot orthoses (custom-made or prefabricated) in PD patients has been found. However, the effectiveness of foot orthoses has been demonstrated for other neurodegenerative disorders [20-22].

Several limitations have been found in this review. The total number of participants in all the studies was 218 (and two studies only included 2 participants). The number is very small; thus, it would be necessary to conduct further studies with increased number of participants In the different investigations, the disease stage and the additional treatment that patients received were not recorded. These factors could modify the effect of the interventions; therefore, they should be considered in the design of future studies. We would also recommend to record "intervention time" as another very important variable. In most studies, the effect of the different interventions was analyzed immediately, and the maximum intervention time was 5 weeks. As shown in Figure 2,75\% of the studies had a high risk of bias in four of the analyzed bias categories. This further complicates obtaining reliable results. To demonstrate the efficacy of these types of treatments in Parkinson's patients, it would be necessary to conduct RCTs with a follow-up period.

\section{Conclusions}

According to the data available from this systematic review, the most important conclusion is that more controlled studies are needed in this research field. There are indications to suggest that textured insoles have positive effects on the gait parameters, stability, and plantar sensation in PD patients. RCTs with a follow-up period would be necessary to demonstrate the efficacy of other types of insoles (footwear modifications, habitual footwear, and foot orthoses).

Supplementary Materials: The following are available online at https:/ /www.mdpi.com/article/ 10.3390/jpm11111136/s1, Search strategy.

Author Contributions: Conceptualization, M.R.-B., D.L.-L. and E.N.-F.; methodology, M.E.L.-I.; software, C.R.-M.; formal analysis, C.R.-M.; investigation, resources, R.B.-d.-B.-V.; data curation, writing—original draft preparation, P.P.-L. and M.R.-B.; writing—review and editing, C.C.-L.; visualization, R.B.-d.-B.-V.; supervision, M.R.-B.; project administration, M.R.-B.; funding acquisition, E.N.-F. All authors have read and agreed to the published version of the manuscript.

Funding: This research was funded by the Generalitat Valenciana, grant number GV/2020/061. 
Institutional Review Board Statement: Not applicable.

Informed Consent Statement: Not applicable.

Conflicts of Interest: The authors declare no conflict of interest.

\section{References}

1. Jenkins, M.E.; Almeida, Q.J.; Spaulding, S.J.; van Oostveen, R.B.; Holmes, J.D.; Johnson, A.M.; Perry, S.D. Plantar cutaneous sensory stimulation improves single-limb support time, and EMG activation patterns among individuals with Parkinson's disease. Park. Relat. Disord. 2009, 15, 697-702. [CrossRef]

2. Brognara, L.; Navarro-flores, E.; Iachemet, L.; Serra-catalá, N.; Cauli, O. Beneficial effect of foot plantar stimulation in gait parameters in individuals with Parkinson's disease. Brain Sci. 2020, 10, 69. [CrossRef]

3. Wijemanne, S.; Jankovic, J. Hand, foot, and spine deformities in parkinsonian disorders. J. Neural Transm. 2019, 126, 253-264. [CrossRef] [PubMed]

4. Pandey, S.; Garg, H. Postural \& striatal deformities in Parkinson's disease: Are these rare? Indian J. Med. Res. 2016, 143, 11-17. [PubMed]

5. Lindholm, B.; Beckman, A.; Duzynski, W.; Ekvall Hansson, E. Outcome on Balance and Gait Following Botulinum Toxin Treatment for Striatal Foot in Parkinson's Disease. Mov. Disord. Clin. Pract. 2017, 4, 309-315. [CrossRef]

6. Qiu, F.; Cole, M.H.; Davids, K.W.; Hennig, E.M.; Silburn, P.A.; Netscher, H.; Kerr, G.K. Effects of textured insoles on balance in people with Parkinson's disease. PLoS ONE 2013, 8. [CrossRef] [PubMed]

7. Novak, P.; Novak, V. Effect of step-synchronized vibration stimulation of soles on gait in Parkinson's disease: A pilot study. J. Neuroeng. Rehabil. 2006, 3, 9. [CrossRef]

8. Lirani-Silva, E.; Vitório, R.; Barbieri, F.A.; Baptista, A.M.; Dos Santos, P.C.R.; Gobbi, L.T.B. Different types of additional somatosensory information do not promote immediate benefits on gait in patients with Parkinson's disease and older adults. Motriz. Rev. Educ. Fis. 2015, 21, 244-249. [CrossRef]

9. Pereira, M.P.; Orcioli-Silva, D.; de Sousa, P.N.; Beretta, V.S.; Gobbi, L.T.B. The effects of habitual footwear in gait outcomes in people with Parkinson's disease. Gait Posture 2019, 68, 111-114. [CrossRef]

10. Mathieson, I.; Curran, S.; Hallam, S.; Corne, J. Improving gait performance in Parkinson's disease: A case report suggesting a role for footwear modifications. Physiotherapy 2008, 94, 85-88. [CrossRef]

11. Debû, B.; De Oliveira Godeiro, C.; Lino, J.C.; Moro, E. Managing Gait, Balance, and Posture in Parkinson's Disease. Curr. Neurol. Neurosci. Rep. 2018, 18, 1-12. [CrossRef] [PubMed]

12. Novo-Trillo, E.; López-López, D.; de Labra, C.; Losa-Iglesias, M.E.; Becerro-De-bengoa-vallejo, R.; Calvo-Lobo, C.; RomeroMorales, C.; San-Antolín-gil, M. Impact of footwear and foot deformities in patients with Parkinson's disease: A case-series study. Int. J. Med. Sci. 2020, 18, 372-377. [CrossRef]

13. Higgins, J.P.T.; Green, S. Cochrane Handbook for Systematic Reviews of Interventions; The Cochrane Collaboration: Bristol, UK, 2019.

14. Moher, D.; Liberati, A.; Tetzlaff, J.; Altman, D.G. Preferred Reporting Items for Systematic Reviews and Meta-Analyses: The PRISMA Statement. PLoS Med. 2009, 6, e1000097. [CrossRef]

15. Urrútia, G.; Bonfill, X. PRISMA declaration: A proposal to improve the publication of systematic reviews and meta-analyses. Med. Clin. (Barc.) 2010, 135, 507-511. [CrossRef]

16. Lirani-Silva, E.; Vitório, R.; Barbieri, F.A.; Orcioli-Silva, D.; Simieli, L.; Gobbi, L.T.B. Continuous use of textured insole improve plantar sensation and stride length of people with Parkinson's disease: A pilot study. Gait Posture 2017, 58, 495-497. [CrossRef] [PubMed]

17. Gaigher, I.; Courau, J.; Pradon, D.; Ziégler, M. Effect of a thermoformed insole associated with a textured coating on the postural control of Parkinson's patients. Rev. du Podol. 2018, 14, 10-12. [CrossRef]

18. Robb, K.A.; Perry, S.D. Textured Foot Orthotics on Dynamic Stability and Turning Performance in Parkinson's Disease. J. Mot. Behav. 2020, 52, 396-403. [CrossRef]

19. Mirelman, A.; Bonato, P.; Camicioli, R.; Ellis, T.D.; Giladi, N.; Hamilton, J.L.; Hass, C.J.; Hausdorff, J.M.; Pelosin, E.; Almeida, Q.J. Gait impairments in Parkinson's disease. Lancet Neurol. 2019, 18, 697-708. [CrossRef]

20. Güner, S.; Haghari, S.; Alsancak, S.; Uluğ, N.; İnanıcı, F. Effect of insoles with arch support on gait pattern in patients with multiple sclerosis. Turkish J. Phys. Med. Rehabil. 2018, 64, 261-267. [CrossRef]

21. Gross, M.T.; Mercer, V.S.; Lin, F.C. Effects of foot orthoses on balance in older adults. J. Orthop. Sports Phys. Ther. 2012, 42, 649-657. [CrossRef] [PubMed]

22. Hatton, A.L.; Dixon, J.; Rome, K.; Brauer, S.G.; Williams, K.; Kerr, G. The effects of prolonged wear of textured shoe insoles on gait, foot sensation and proprioception in people with multiple sclerosis: Study protocol for a randomised controlled trial. Trials 2016, 17. [CrossRef] [PubMed] 